\title{
Using geophysics on a terminal moraine damming a glacial lake: the Flatbre debris flow case, Western Norway
}

\author{
I. Lecomte ${ }^{1,2}$ I. Thollet $^{3, *}$, H. Juliussen ${ }^{4, * *}$, and S.-E. Hamran ${ }^{4}$ \\ ${ }^{1}$ International Centre for Geohazards, P.O.Box 3930, Ullevaal Stadion, 0806 Oslo, Norway \\ ${ }^{2}$ NORSAR, P.O. Box 53, 2027 Kjeller, Norway \\ ${ }^{3}$ University of Strasbourg, EOST, 5 rue René Descartes, 67084 Strasbourg Cedex, France \\ ${ }^{4}$ University of Oslo, P.O. Box 1047, Blindern, 0316 Oslo, Norway \\ *now at: University of Nancy, France \\ *** now at: University of Svalbard, Longyearbyen, Norway
}

Received: 23 July 2007 - Revised: 17 April 2008 - Accepted: 18 April 2008 - Published: 24 April 2008

\begin{abstract}
A debris flow occurred on 8 May 2004, in Fjærland, Western Norway, due to a Glacial Lake Outburst Flood and a natural terminal moraine failure. The site was investigated in 2004 and 2005, using pre- and post-flow aerial photos, airborne laser scanning, and extensive field work investigations, resulting in a good understanding of the mechanics of the debris flow, with quantification of the entrainment and determination of the final volume involved. However, though the moraine had a clear weak point, with lower elevation and erosion due to overflowing in the melting season, the sudden rupture of the moraine still needs to be explained. As moraines often contain an ice core, a possible cause could be the melting of the ice, inducing a progressive weakening of the structure. Geophysical investigations were therefore carried out in September 2006, including seismic refraction, GPR and resistivity. All methods worked well, but none revealed the presence of ice, though the depth to bedrock was determined. On the contrary, the moraine appeared to be highly saturated in water, especially in one area, away from the actual breach and corresponding to observed water seepage at the foot of the moraine. To estimate future hazard, water circulation through the moraine should be monitored over time.
\end{abstract}

\section{Introduction}

Glacier retreat is observed around the world and is usually associated with global warming. Beside the fact that glaciers are the major source of water for many local communities, especially in tropical areas like in the Andes, the retreat of a glacier can result in the formation of glacial lakes behind the

Correspondence to: I. Lecomte

(i1@geohazards.no) moraine. These lakes may then overflow during periods of high water discharge from the glacier (glacier lake outburst flood, or GLOF), generating impressive and often devastating debris flows, which are a threat to the local population, as often seen in Peru at the Cordillera Blanca (Lliboutry et al., 1977).

The 2004 debris flow in Fjærland, Western Norway, developed from a failure of a glacial moraine ridge, which caused the sudden drainage of the lake behind and possibly also a lake contained within the Flatbre glacier. A total soil and boulder volume of about $240000 \mathrm{~m}^{3}$ terminated in a boulder fan $3 \mathrm{~km}$ downstream, while the finer material inundated fields and nearby areas. The initial volume of tilt at the moraine ridge is estimated to be $25000 \mathrm{~m}^{3}$, showing a significant bulking as the masses cascaded down the valley. The volume of the lake itself behind the moraine was about $50000 \mathrm{~m}^{3}$, but the volume of the water coming from under the glacier is unknown.

Early drainage from the glacier and blockage of the normal drainage routes, combined with a weakening of the moraine ridge, may have triggered the event (overtopping). In a warming climate, a likely scenario in many high mountain glacial regions is the melting of ice cores and internal erosion of moraines damming glacial lakes, leading to dam ridge failure when high drainage occurs. To evaluate whether geophysics could be useful for investigation of the inner structure of the moraine, a geophysical campaign was performed in September 2006, consisting of resistivity, Ground-Penetrating Radar (GPR) and seismic refraction. A new type of rough terrain antenna was tested for the GPR. The goal was not only to perform geophysical investigation of a specific site, but also to evaluate the different methods in terms of practibility, cost and returned value. Based on the recommendations given by Reynolds (2006), both GPR and

Published by Copernicus Publications on behalf of the European Geosciences Union. 


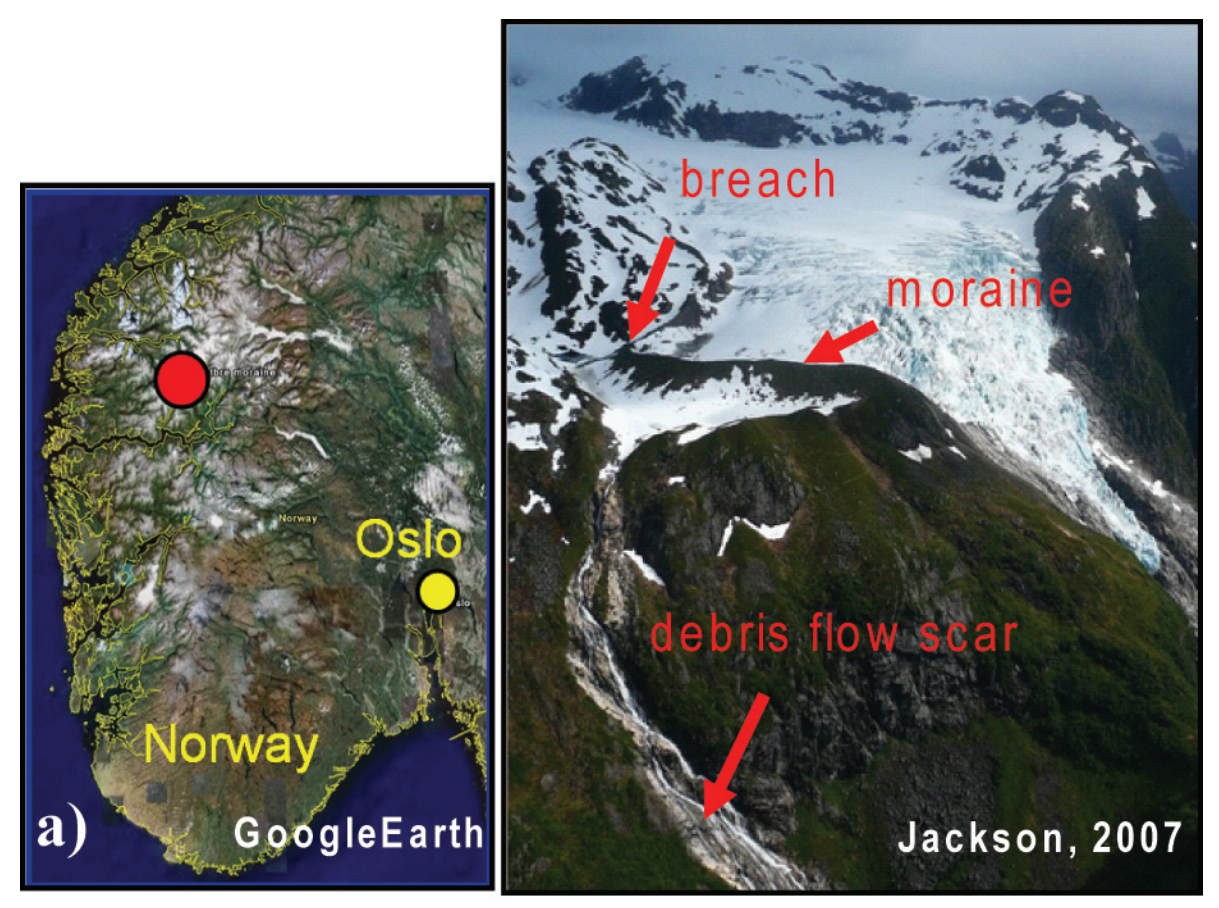

Fig. 1. (a) Location of the site in Western Norway. (b) Overview of the site.

resistivity were chosen as the methods of choice. In addition the seismic refraction technique was used despite the problems usually encountered by such a technique (bad coupling of the receivers to the ground, loose material, etc.).

\section{The Flatbre site}

The site is located in Western Norway, in the Fjaerland region (Fig. 1a, red dot). The terminal moraine of Flatbre at about $1000 \mathrm{~m}$ a.s.l. (Fig. 1b) was probably formed in the Little Ice Age and was damming a small lake due to the last hundred years of glacier retreat (Jackson, personal communication). The moraine is about $650 \mathrm{~m}$ long, with heights between 25 and $50 \mathrm{~m}$, and a slope from about $30^{\circ}$ downstream to more than $35^{\circ}$ upstream. The material of the moraine is from the Late Holocene and has minimal clay content, hence is easily eroded. The scar of the debris flow is still visible on a picture taken 3 years later (Fig. 1b). Figure 2 shows the moraine right after the 2004 GLOF with a clear breach through which water from both the lake and from below the glacier escaped. Note also an old moraine in the background, and a small new moraine against the principal one. The new moraine is icecored, as easily observable in the field, with ice just beneath the moraine surface.

Thorough studies of the 2004 Flatbre debris flow and its possible causes can be found in Breien (2005) and Breien et al. (2008), especially regarding the dynamic of the debris flow. Key glaciologic information was also provided by the Norwegian Water Resources and Energy Directorate
(NVE, M. Jackson, personal communication). The site is at about $1000 \mathrm{~m}$ a.s.l., i.e., below the normal permafrost elevation in Norway (about 1400-1600 m a.s.l.; Etzelmüller et al., 2003). But local conditions may lower this limit; the site is at the edge of the largest glacier on the European continent; i.e., the Jostedalsbreen glacier. The small lake behind the moraine is regularly emptied each year (seasonal activity), but mostly subglacially, draining out to the regenerated outlet glacier Supphellebreen (steep down-going part of the glacier in Fig. 1b). No damage is reported for such events and the site was therefore not considered as potentially dangerous (Vaksdal and Melvold, 2003). However, events similar to the one in 2004 may have occurred in 1924 and 1947, although not on such a large scale as in 2004 (Breien, 2005). In 2004, E. Øygard, owner of both the nearby farm in the valley and the cabin close to the moraine, was a witness of the GLOF and subsequent debris flow, and took photographs (Fig. 3a). The violence of the event is clearly demonstrated by the depth of the erosion along the flow path (Fig. 3b), the size of the flooded area in the valley (Fig. 3c) with a total run-out of about $3 \mathrm{~km}$, and the size of the transported boulders (Fig. 3d).

The Flatbre moraine in Fjaerland is a good candidate for a field laboratory site and as much data as possible was collected to better understand what happened and why. In addition, testing of geophysical methods and equipment is possible, which allows evaluation of which methods give useful results. Glacier hazards are difficult to investigate due to their remoteness (Reynolds, 2006). Though helicopter 


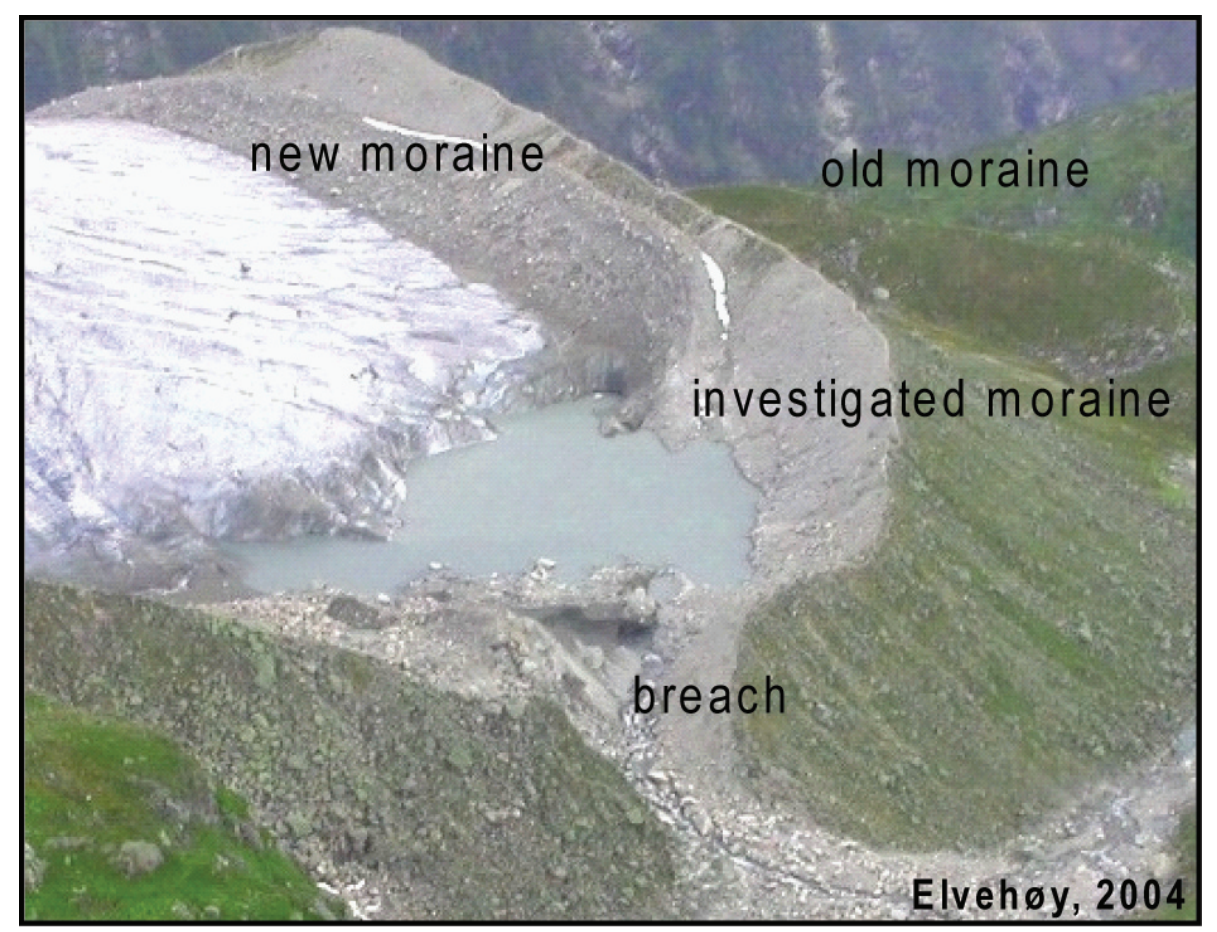

Fig. 2. Aerial photography of the moraine site after the 2004 GLOF.

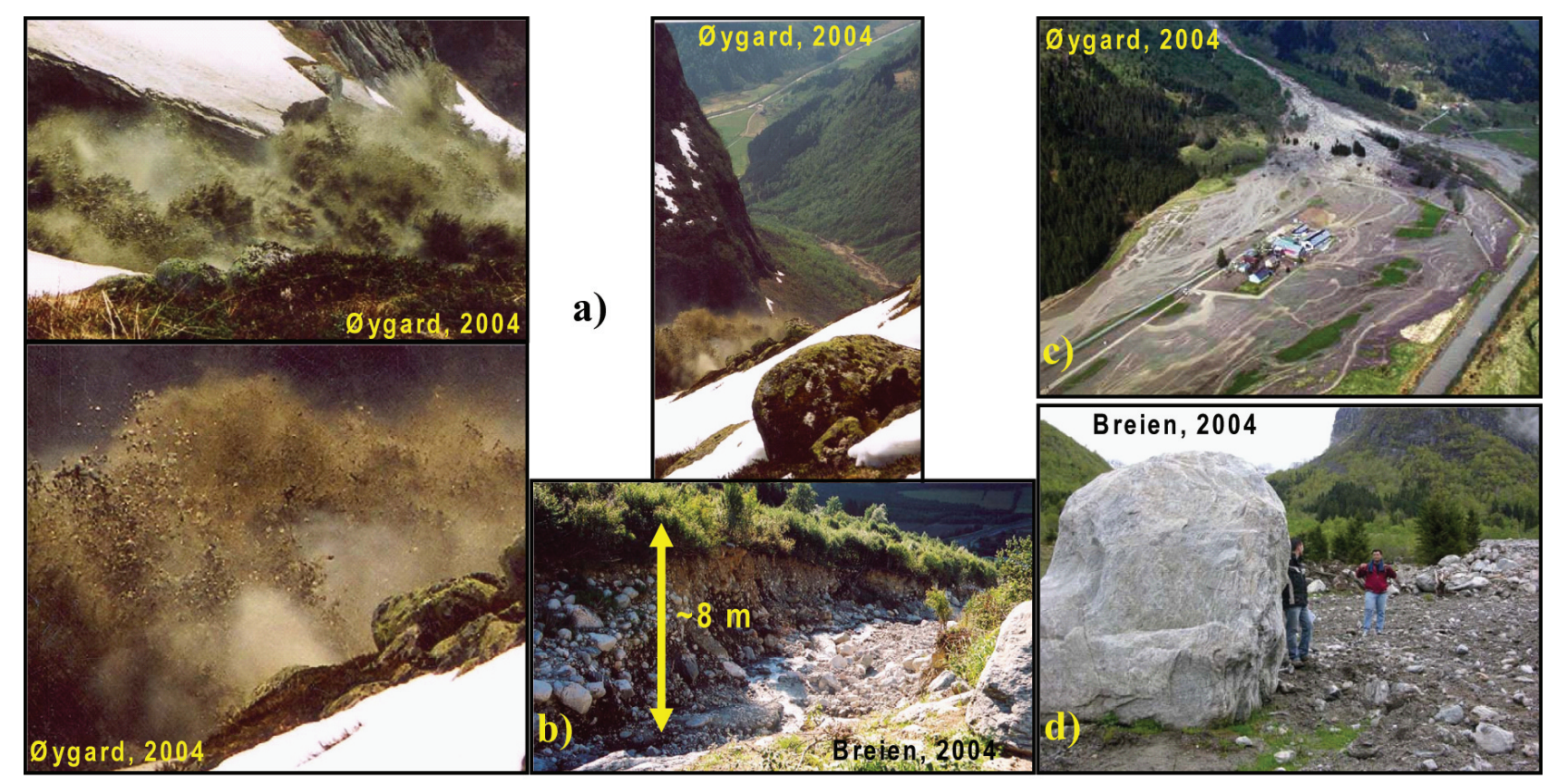

Fig. 3. (a) Photographs taken by E. Øygard during the 8 May 2004, GLOF. (b) Erosion along the path of the flow. (c) Boulder fan and part of the mud flooded area. (d) Example of transported boulders down in the valley.

transportation is a necessity at Flatbre, the cost is reasonable as the flight takes only a few minutes. Such case studies are useful to gain experience and should be done, especially in countries like Norway which can afford the cost. As glacier retreat is observed all over the world, and believed to be associated with global warming, it is of major importance for the international society to learn more about glacier hazards for better prevention and mitigation in the future. 



b)

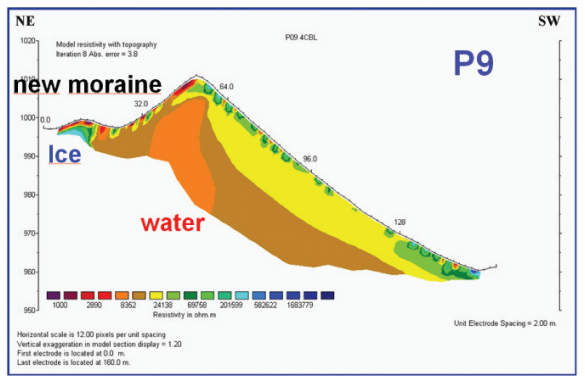

Fig. 4. Electrical resistivity data. (a) Location of the profiles. (b) Examples of electric tomography profiles, with P3 and P9 showing both very low resistivity down in the main moraine (high water saturation) and very high resistivity (ice in the new moraine). The old moraine shows intermediate values.

\section{Geophysical investigations}

Several types of geophysical measurements were carried out in September 2006. Our goal was to use standard methods and processing software to evaluate their applicability in such a difficult terrain. The development of near-surface geophysics has been significant in the last 10 years, with much better equipment and software now available. Beside the separate development of various techniques, the trend is now to integrate several types of measurements for joined inversion/interpretation (Grandjean, 2006), which is a promising approach which leads to less uncertainty.

\subsection{Resistivity}

Resistivity measurements are useful in permafrost areas and have been proved to work well on similar moraine investigations (Reynolds, 2006). Except for the transport of the equipment, done here with helicopter, the equipment is rather easy to install and operate (electrodes in the ground), but the measurements take time. The data can be easily processed in the field, on the same day, giving quick, valuable information.

\subsubsection{Equipment and setting}

We used an ABEM Lund multi-electrode Terrameter SAS 300 system, with $40 \mathrm{~m}$ cables ( 2 to 5 cables depending on the profiles), and $2 \mathrm{~m}$ spacing between the electrodes. The Wenner configuration was chosen and the standard Res2DInv software used for the data inversion. Due to the time needed for the acquisition of each profile (about $2 \mathrm{~h}$ ), in addition to the installation, only 7 profiles were acquired during the 3 days on site (Fig. 4a).

\subsubsection{Results}

Figure $4 \mathrm{~b}$ shows four of the profiles. On both profiles P3 and $\mathrm{P} 9$, the acquisition line went through the new moraine, which explains the very high observed resistivity values (above $200000 \mathrm{Ohm} \mathrm{m}$, blue colors), characteristic of ice. As one of the questions to be answered by using geophysics was the presence of ice in the moraine, the resistivity profiles gave us a quick answer, i.e., no ice core observed in the penetrated area, observation later confirmed by both GPR and seismic refraction. On the contrary, the inner part of the main moraine is characterized by rather low resistivity values (the opposite side of the scale, red-brownish colors) indicating a progressive water saturation of the moraine material with depth. Profiles P6 to P8 show the lowest resistivity value, and this corresponds to a zone of the moraine where water seepage is observed at its foot (Fig. 4c). Note that this zone is away from the breach and may indicate a preferential path of water flow through the moraine.

\subsection{GPR}

Gound-Penetrating Radar (GPR) techniques are also reported to work well in permafrost areas and on moraines (Reynolds, 2006). The data acquisition can be difficult and time-consuming, especially with the standard antennas, though the result is more or less directly available on the 

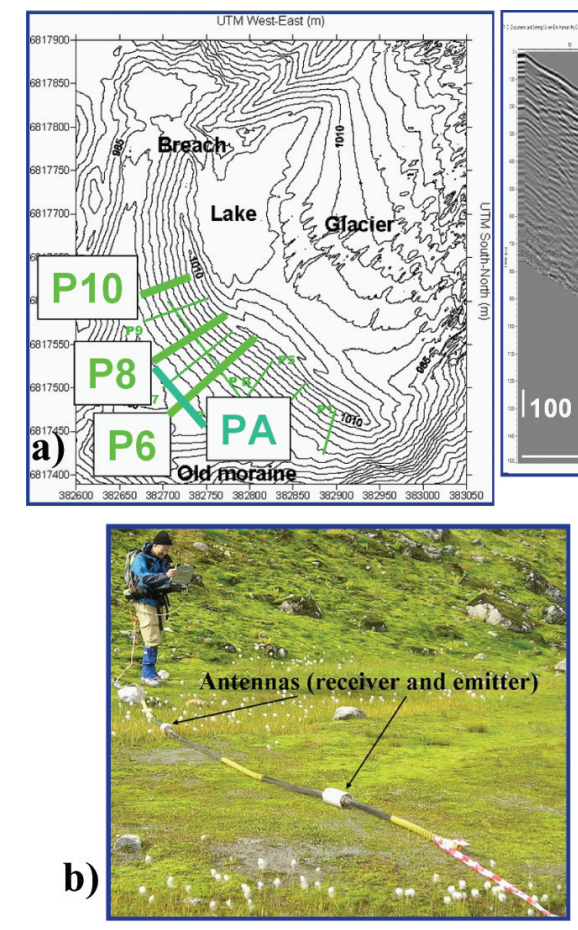
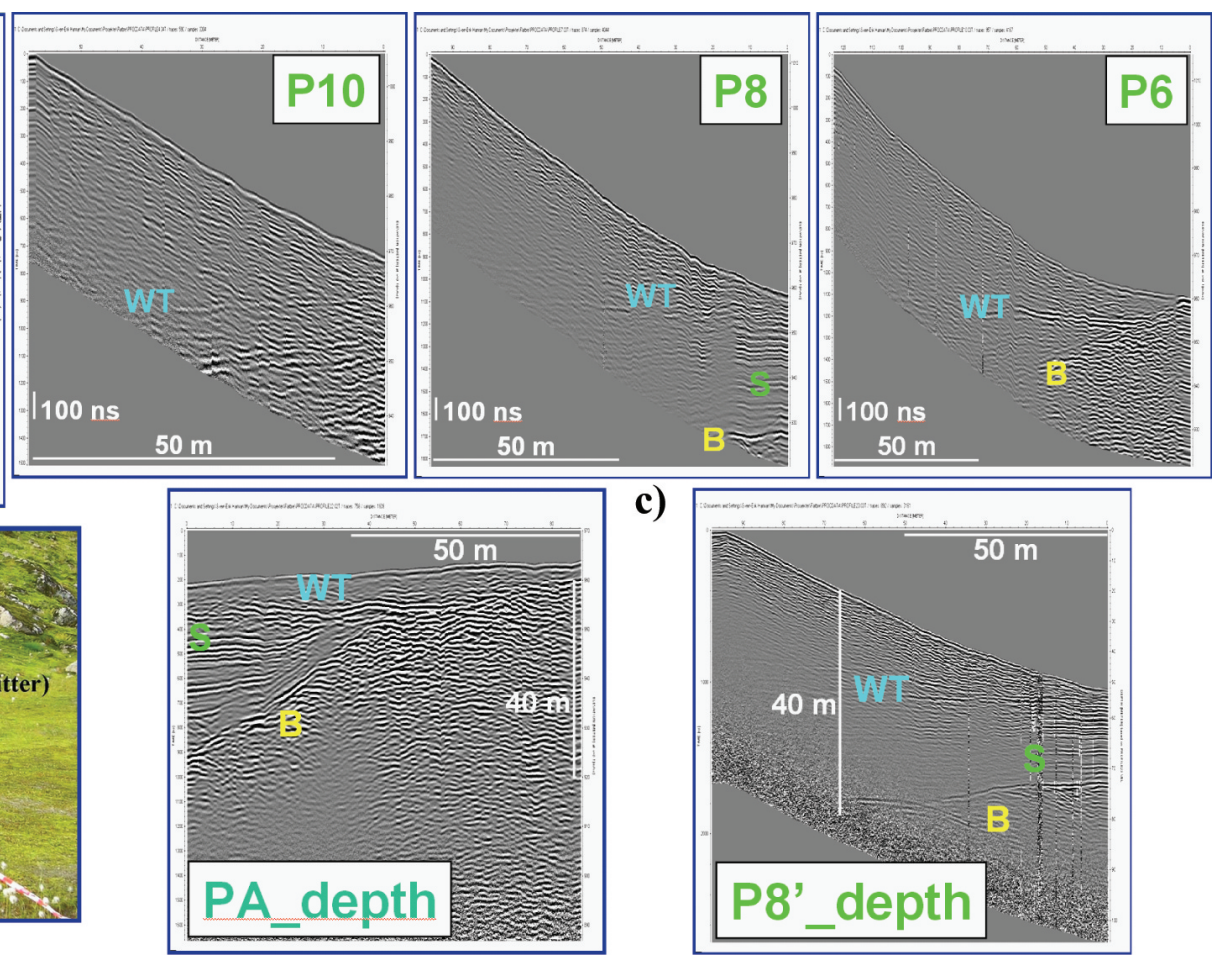

c)

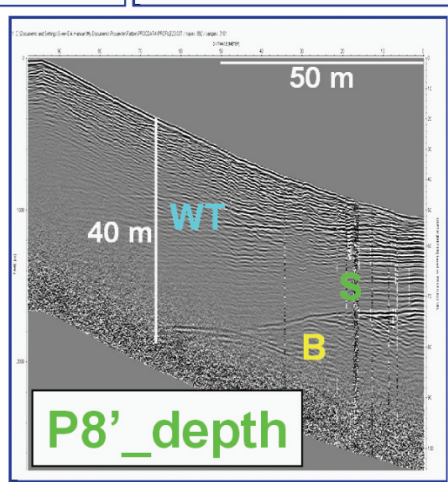

Fig. 5. GPR. (a) Location of the profiles. (b) $50 \mathrm{MHz}$ cquisition system with both emitting and receiving antennas on the same rod and pulled by an operator (c) Examples of processed profiles, the upper ones being in time, and the lower ones obtained after depth conversion. Water-table like reflectors (WT), bedrock (B) and lake-deposit sediments (S) are identified.

screen of a laptop in real-time as a radar section in time, often quickly translated to depth.

\subsubsection{Equipment and settings}

We had both standard non-shielded antennas (25 and $50 \mathrm{MHz}$ ) and a new rough-terrain $50 \mathrm{MHz}$ antenna of Malå (Fig. 5b). We quickly found out that the latter was the perfect tool to use on the moraine due to numerous and often large boulders covering it and preventing the use of the long antennas. The acquisition was so efficient compared to the standard antennas that all profiles in Fig. 5a were more or less acquired within a day.

\subsubsection{Results}

The data were processed using ReflexW. Though the structure inside the moraine is quite heterogeneous, with different grain sizes from rather fine sand to large boulders, the GPR results showed several interesting features with clear reflectors down to 30-40 $\mathrm{m}$ in depth (Fig. 5c). Some are associated with water-table like features (strong and near horizontal reflectors, see P6). Others are typical layered structures (in PA and P8) believed to be lake deposits in an older lake trapped by the older moraine. In addition, bedrock is clearly reached in several profiles. Strong diffractions at dipping bedrock can be seen along Profile PA at the foot of the moraine, thus giv- ing the possibility to estimate velocities at several depths in order to properly convert from time to depth (bottom profiles in Fig. 5c). A velocity in the main moraine and a different one in the lake deposits were then used.

Despite a chaotic image inside the top part of the moraine due to interfering diffractions on boulders, the water-table like reflectors seem to correspond to the zones of higher water content detected by resistivity. The rather fine layered structure below the moraine may also channelize water from the glacier and under the moraine, which may in turn increase its internal erosion.

\subsection{Refraction seismic}

In contrast with resistivity and GPR techniques, seismic refraction data are much more complicated to acquire and process, and are generally of poor quality in coarse and sandy material (Reynolds, 2006). While on site, we usually just get a first guess of the information contained in the data, but sometimes long and difficult processing are needed after field work (event picking). As with the GPR data, we used ReflexW as the standard software.

\subsubsection{Equipment and settings}

We used a 24-channel Geode (Geometrics) with 24 vertical geophones and 5-kg hammer-blows as source after 

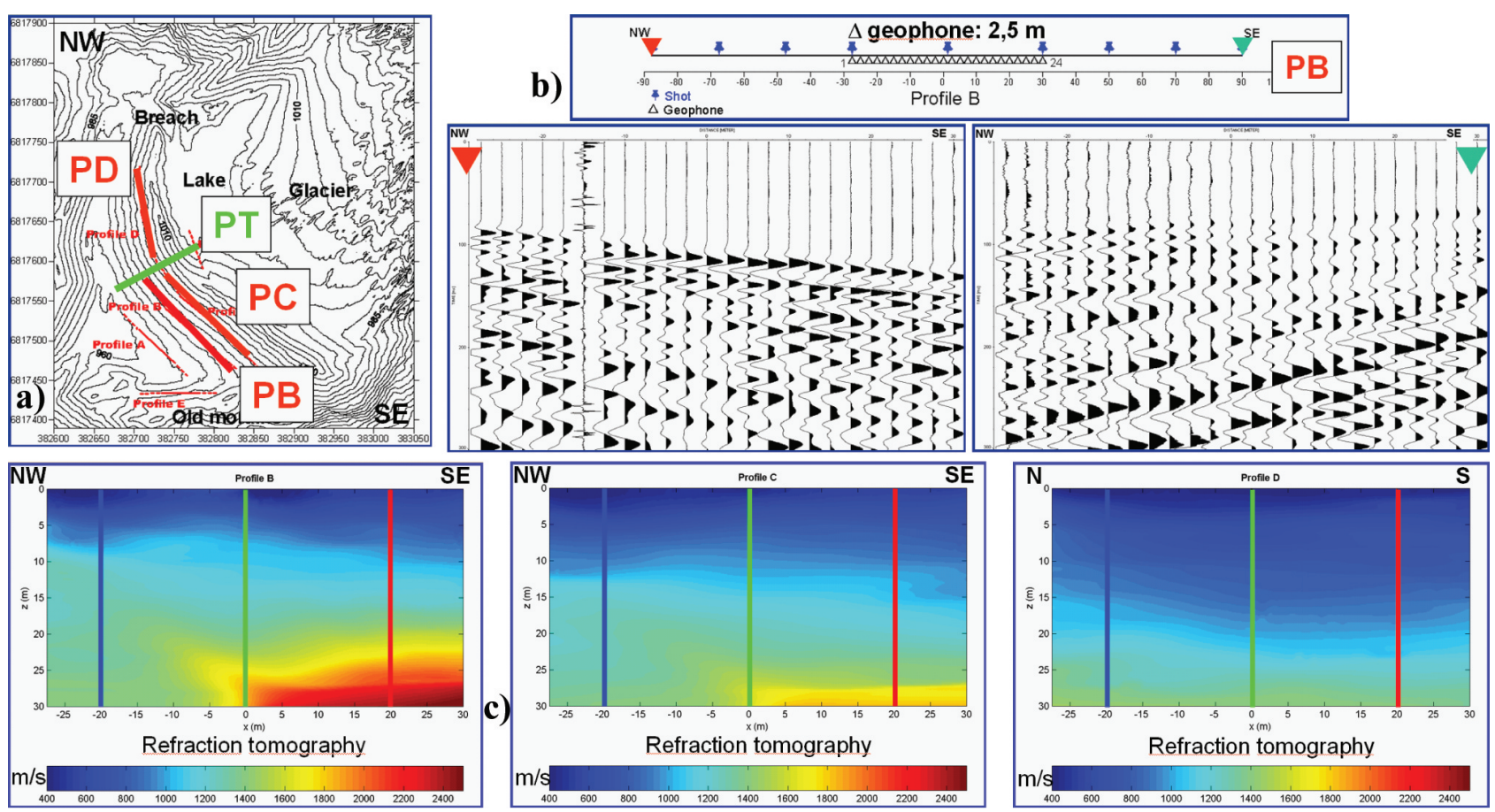

Fig. 6. Seismic refraction data. (a) Location of the profiles. (b) Example of 2 shots for one of the profile (PB). (c) Refraction tomography results for 3 profiles.

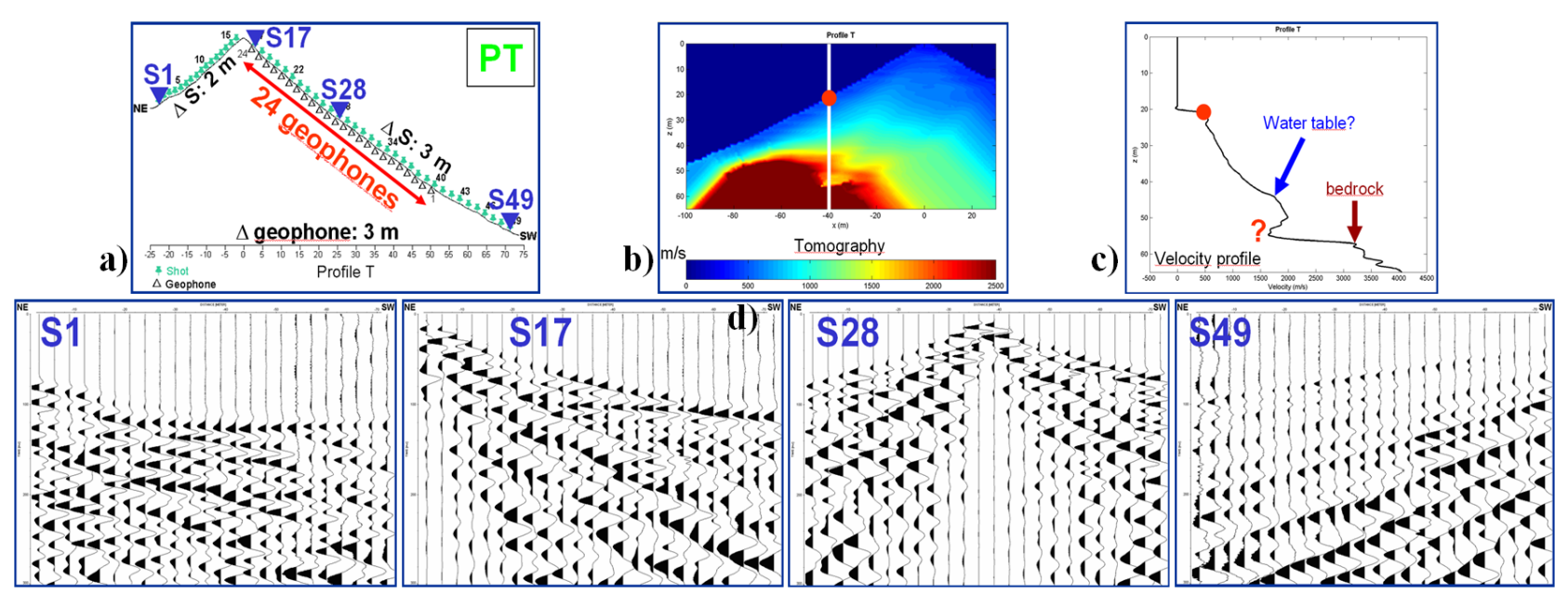

Fig. 7. Seismic refraction data (2). (a) Geometry of the transverse profile (see location in Fig. 6a) with 24 fixed geophones and 49 hammerblow positions. (b) Final tomography result. (c) Vertical velocity profile at the lateral position given in (b). (d) Examples of shot recordings.

comparison with a seismic gun (Betsy gun). The use of the latter was difficult, slowing down significantly the acquisition without giving better results. Five standard refraction profiles were acquired, three on the main moraine, one on the old one and one at the foot of the moraine, all along the corresponding moraine axis, the sampling between geophones being $2.5 \mathrm{~m}$ (Fig. 6a). In addition, a line across the main moraine was acquired with denser shots and with the 24 geo- phones located on the distal side every $3 \mathrm{~m}$ (PT in Fig. 6a with a cross-section given in Fig. 7a; one day was needed for that profile only).

\subsubsection{Results}

The seismic refraction data were of very good quality and hammer blows were sufficient for offsets up to $80 \mathrm{~m}$ from the receiving line extremities (Fig. 6b). The data were 
systematically of better quality above the wetter zone identified by both resistivity and GPR, while showing weaker firstarrivals away from that zone, either towards the breach or on the South-East side. We used the wavefront-based tomography approach of ReflexW to produce tomograms, as in Fig. 6c and Fig. 7b. No ice-velocity is found within the moraine, in agreement with resistivity. Within the moraine, the velocity increases with a rather linear gradient (compaction and/or capillarity-induced water content) up to waterlike velocities, followed by a transition zone believed to correspond to the highly water-saturated sediment package, before reaching the bedrock (Fig. 7c). The good quality of the data, also shown in Fig. 7d, was unexpected and a denser acquisition in lines, receivers and shots, would have permitted a 3-D tomography.

\section{Conclusions}

All techniques worked well, providing useful information, despite a very blocky moraine material. There is, for example, no evidence of ice, at least at the penetrated depths (30$40 \mathrm{~m}$ ). On the contrary, the moraine is quite wet, characterized by low resistivity in contrast to icy material closer to the glacier, seismic velocities typical of water-saturated material, and clear water tables visible within the GPR data. The depth to bedrock is determined at the base on the distal side using both GPR and seismic refraction. The very good quality of the seismic refraction data, usually poor on such moraine material, is an additional indication of high water content. Both resistivity and GPR are very efficient techniques, providing results while on site. Seismic refraction is more difficult to use, but its results, when combined with those of the two previous mentioned techniques, give a more complete image of the moraine. A zone of apparently higher water content was identified and may require continuous monitoring to better assess the water flow inside the moraine. Geophysical methods such as resistivity monitoring, self-potential (SP) measurements, and hydrological measurements could be used for that purpose. It is also necessary to map the bedrock to define its topology and low-frequency GPR could help doing so (acquisition on snow at the end of the winter).

Judging from the quality of the collected seismic refraction data, the recording time-window should have been increased (up to $1 \mathrm{~s}$, for instance) to allow complete recording of surface waves, especially their fundamental mode. These waves are good indicators of the shear strength of a geological structure. Despite our short time-window, preliminary processing of surface-wave data gave interesting results, especially shear-wave velocity $1-D$ profiles and 2 -D sections, which complete the compressional-wave results (A. Bitri, BRGM, personal communication). In addition, joined inversion/interpretation of the different data sets, based on several types of measurements, could better constrain all of the results and lead to clearer conclusions. The data are available for external studies and the Flatbre site could be considered as a field laboratory in the future, especially in view of the proximity of the Norwegian Glacier Museum in Fjaerland.

Acknowledgements. First of all, the authors would like to thank the students who helped us in the field, i.e., May Bagge-Lund, Alban Souche and Maria Sand. We also thank Hedda Breien for bringing up the case to us, and Karl Joseph Sandmeier for his help with ReflexW. Thanks to the Norwegian Research Council and the International Centre for Geohazards. Many thanks to the field work sponsors: the Norwegian Glacier Museum (Lisbeth Vedaas), NORSAR, the Norwegian Geotechnical Institute and the Geological Survey of Norway. Thanks to T. Dybwad from the regional municipality of Sogn og Fjordane for the authorization to work in a national park. Many thanks go to G. and E. Øygard for their cabin and hospitality! Last but not least, thanks to our ICG colleagues, who followed the case and with whom we had many interesting discussions, and to NVE (Miriam Jackson) for providing additional information and material. This publication is ICG contribution \#191.

Edited by: P. Lagos

Reviewed by: M. Larsen and B. McArdell

\section{References}

Breien, H.: On the dynamics of debris flows: Case study Fjaerland, Western Norway - a debris flow triggered by a natural dam breach, Master thesis in Geosciences, University of Oslo, 2005.

Breien, H., Elverhøi, A., De Blasio, F., and Høeg, K.: Erosion and morphology of a debris flow caused by a glacial lake outburst flood, Western Norway, Landslides, doi:10.1007/s10346008-0118-3, in press, 2008.

Etzelmüller, B., Berthling, I., and Sollid, J.L.: Aspects and concepts on the geomorphological significance of Holocene permafrost in southern Norway, Geomorphology, 52, 1-2, 87-104, 2003.

Grandjean, G., Malet, J.-P., Bitri, A., and Méric, O.: Geophysical data fusion by fuzzy logic for imaging the mechanical behaviour of mudslides, Bull. Soc. Geol. France, 178(2), 127-136, 2007.

Lliboutry, L., Morales Arnao, B., and Schneider, B.: Glaciological problems set by the control of dangerous lakes in Cordillera Blanca, Peru, I. historical failures of morainic dams, their causes and prevention, J. Glaciol., 18(79), 239-254, 1977.

Reynolds, J. M.: Role of geophysics in glacial hazard assessment, First Break, 24, 61-66, 2006.

Thollet, I.: Glacial hazards and Geophysics: study of the Flatbre moraine after a glacial lake outburst flood (Western Norway), Dipl. Eng. Geophys. Thesis, University of Strasbourg, ICG report T1-2006-1, 2006.

Vaksdal, M. and Melvold, K.: Glacier Inventory in Norway, Survey and prevention of extreme glaciological hazards in european mountainous region, GLACIORISKS, EU 5th Framework Programme, EVG1 2000 00512, compiled by D. Richards and M. Gay, 2003. 